\title{
Mujeres angoleñas en la lucha anticolonial: historiografía, fuentes y memoria
}

\author{
Angolan women in the anti-colonial struggle: historiography, \\ sources, and memory
}

\author{
Dayane Augusta Santos da Silva \\ Instituto Federal de Brasilia (Brasil) \\ daygusta@gmail.com
}

\begin{abstract}
Resumen
Las narrativas de lucha contra la colonización han sido construidas en masculino con base en documentos producidos por hombres y, por tanto, las mujeres han ocupado un espacio periférico en esas narrativas. En Angola, en el campo de la Historia de las mujeres, es reciente una perspectiva crítica de escritura en femenino o en pro de las mujeres y producida por mujeres. En este sentido, la temática de las mujeres angoleñas deviene importante para comprender las dinámicas sociales de una Angola contemporánea. Para ello, este trabajo invita a investigadores de diferentes áreas, principalmente historiadores, a repensar la historiografía sobre/de las mujeres angoleñas, considerando la forma en que se construyeron narrativas que atendieran a necesidades teóricas y prácticas "localizadas", a partir del contexto de liberación nacional.
\end{abstract}

\section{Palabras Clave}

Mujeres; Experiencia; Historiografía; Lucha anticolonial.

\begin{abstract}
The narratives of the fight against colonization have been constructed as masculine, based on documents produced by men and, therefore, women have occupied a peripheral space in these narratives. In Angola, in the field of Women's History, a critical perspective of writing in the feminine or writing produced by women is recent. In this sense, the theme of Angolan women is important to understand the social dynamics of contemporary Angola. To this
\end{abstract}

\footnotetext{
${ }^{1}$ Este artículo es resultado de la ponencia presentada en el Coloquio "As Mulheres na Clandestinidade e na Guerrilha. O papel das mulheres na Luta de Libertação Nacional: 1950-1975", realizado por la Biblioteca Nacional de Angola, en el ámbito del Ministerio de Cultura, en Luanda, entre los días 27 y 28 de marzo de 2019. El texto original fue presentado por la autora en portugués, su traducción estuvo a cargo de Paola Marugan Ricart.
}

Esta obra está sujeta a la Licencia Reconocimiento-NoComercial-CompartirIgual 4.0 Internacional de Creative Commons. http://creativecommons.org/licenses/by-nc-sa/4.0/ 


\section{Dayane Augusta Santos da Silva}

end, this work invites researchers from different areas, but mainly historians, to rethink the historiography about / by Angolan women in the way narratives that meet the "mandatory" theoretical and practical needs were constructed in the context of national liberation.

\section{Keywords}

Women; experience; historiography; anticolonial struggle.

Este artículo es parte de la discusión que presento en mi investigación de doctorado sobre la experiencia de mujeres angoleñas en la lucha anticolonial entre $1961 \mathrm{y}$ $1975 .^{2}$ Por medio de fuentes de diversa naturaleza, localizadas en archivos de Angola y Portugal, tales como periódicos, fotografías, postales, panfletos, documentos e informes oficiales y varias entrevistas, esta investigación busca registrar las diferentes facetas de actuación de mujeres anónimas, principalmente campesinas, concebidas como guerrilleras en el desarrollo de "tareas militares" que ejecutaban en las bases de los movimientos de liberación. Cortar cafeto en los cafetales y atender las plantaciones bananeras, dar mantenimiento a las carreteras, cavar fosas para impedir la circulación de vehículos, preparar kisaka ${ }^{3}$ pisada, harina de maíz y trabajar en el arado de las tierras de cultivo, son las ocupaciones que estas mujeres desempeñaban, llamadas por ellas mismas "trabajos de la revolución", tareas constituidas como acciones fundamentales para la guerra en la cobertura y trabajo logístico de retaguardia.

El principal motivo de esta investigación fue crear condiciones a través de una revisión historiográfica y documental para que esas mujeres afirmasen sus voces y hacer visibles sus capacidades de elección en el contexto de la guerra de liberación nacional. Surge, entonces, con la voluntad de constituir un aporte a la discusión historiográfica en la que este artículo se inscribe.

De este modo, presento el debate historiográfico organizado conforme a la realización del trabajo de campo, con base en una metodología de historia oral con mujeres campesinas, que participaron en las bases militares de los movimientos de liberación. El texto fue estructurado en tres partes. En la primera, presento la lucha de liberación, para fundamentar el surgimiento del/de los pensamiento(s) feminista(s) africano(s) en la formulación de un conocimiento sistematizado y organizado a partir de los años setenta del siglo XX. Así, muestro un panorama de la presencia y visibilización de mujeres africanas en la lucha anticolonial y a continuación, la participación de algunas de estas mujeres en las discusiones públicas de la vida nacional angoleña, durante el periodo pos independendiente. Además, elaboro una reflexión crítica sobre la escritura de la historia de Angola, considerando que ésta privilegia las narrativas masculinizantes y cuando menciona a las mujeres lo hace a partir del "carácter ejemplar", de la figura de la mujer heroica,

\footnotetext{
${ }^{2}$ En el Doctorado correspondiente al Programa de posgrado en Historia de la Universidad de Brasilia.

${ }^{3}$ La kisaka o Quizaca es un plato típico de la cocina tradicional angoleña hecho de las hojas de la planta de yuca. (N.T.)
} 


\section{Mujeres angoleñas en la lucha anticolonial: historiografía, fuentes y memoria}

impidiendo que los observadores conozcan otras memorias y protagonistas de la Historia.

En la segunda parte del artículo desarrollo la discusión historiográfica producida en Angola y en el exterior sobre las mujeres angoleñas en las guerras, principalmente los debates que las sitúan en el contexto de la lucha anticolonial contra el régimen portugués. En estas discusiones, me interesa el lugar de enunciación de las sujetos africanas, especialmente las campesinas, su agencia y protagonismos. Finalmente, en la tercera parte busqué sistematizar las ideas presentadas a lo largo del texto, no con intensión de concluir y agotar el tema, sino más bien de tejer algunas consideraciones finales sobre el texto.

De manera general, el artículo pretende reflejar sucintamente, desde una perspectiva multidisciplinar y a partir de investigaciones académicas de investigadorxs angoleñxs y extranjerxs, el campo de estudios de género en el país. Esta área de estudios ha ido configurándose a lo largo del tiempo y ha sido formulada a partir de estudios que presentan nuevas propuestas de investigación y de análisis en la demarcación de un posicionamiento contra la esencialización y universalización de las experiencias.

\section{Sobre el campo de estudios de las mujeres en Angola}

En Angola los feminismos africanos se constituyeron a partir de los años 70 de la segunda mitad del siglo XX en la acepción tradicional de la lucha contra las opresiones y pro-derechos de las mujeres. Se sabe que la lucha por la igualdad de derechos adquirió una progresiva expresión con las guerras de descolonización. Desde entonces, las mujeres se convirtieron en participantes activas en varias actividades y campos de combate, "obteniendo, así en parte la admiración y el respeto de sus "camaradas" o compañeros, no obstante, sabiéndose poco de su participación política activa" (Ferreira, 2018, 54).

El feminismo, en los términos conocidos en occidente, contó con pocas expresiones en el contexto angoleño. No en vano, en las noticias de los periódicos consultados entre los años 1960 y 1975, solo encontré vestigios de las pautas de los movimientos feministas del exterior, principalmente de Estados Unidos y Europa. En uno de los periódicos, el Provincia de Angola, localicé para febrero de 1972 una foto pequeña de Angela Davis con sus dos dientes delanteros pintados y una breve referencia que discurría sobre su dispensa "bajo fianza y tras 16 meses de prisión". Davis declara en la nota: "me siento perfectamente capaz de defender hasta el fin mi causa justa".4 Sin embargo, es innegable que en el siglo XX hubo "movimientos" de mujeres angoleñas en las luchas por la independencia, que combatieron al "lado de los hombres", como recurrentemente aparece en los relatos de época y que, a partir de

\footnotetext{
${ }^{4}$ Archivo de la Biblioteca Nacional de Angola. Periódico Provincia de Angola, febrero de 1972.
} 


\section{Dayane Augusta Santos da Silva}

ello, pasaron a teorizar sobre sus propias experiencias ${ }^{5}$. Las luchas de liberación sirvieron como base de formación para los feminismos africanos ${ }^{6}$, por lo que éstos se confunden y se insertan en la lucha política por la independencia de Angola (Ferreira, 2018, 55). Tal hecho no quiere decir que antes no hubiese lideresas organizadas en Angola, pero no las hubo en los términos de los feminismos occidentales de la década de los 60.

Es posible considerar que la lucha por la igualdad de derechos, como una conquista colectiva de mujeres, se remonta al siglo XIX, al igual que el concepto "feminismo". De ese periodo ${ }^{7}$-principalmente en los países de lengua portuguesa-, existen pocos estudios conocidos sobre cómo las mujeres angoleñas "se regían por y podían reaccionar de varias formas a las costumbres que les impuso la sociedad de la época" (Ferreira, 2018, 54). Una excepción es Dya Kassembe (2010), escritora angoleña todavía poco conocida en la academia brasileña, quien presenta una producción literaria y ensayística importante sobre Angola. La autora organizó un libro de relatos y memorias sobre la tradición de las mujeres de Kisama, antigua región angoleña que se extendía por un amplio territorio, del Kwanza Norte al Kwanza Sur. En el libro titulado: As mulheres honradas e insubmissas de Angola (Las mujeres honradas e insumisas de Angola), Kassembe reflexiona sobre las "mujeres de la Angola pre colonial, el proceso de aprendizaje que ellas vivenciaron como las más veteranas y las estrategias que hallaban para, a partir del espacio que la tradición les confería, construir su autonomía y reconocimiento social" (Rabello, 2007, 126). La autora busca "recuperar la propia historia, para fortalecer la identidad y promover la autonomía" (Rabello, 2007, 127). Si bien existen investigaciones todavía en proceso sobre las mujeres de la Angola pre colonial, dentro y fuera del país, ${ }^{8}$ cabe preguntarse ¿cuántas otras situaciones que no conocemos deben haber existido acerca de las formas de contestación al orden vigente? Podemos

\footnotetext{
${ }^{5}$ Utilizo el término "movimientos", deliberadamente, para sugerir la movilización de mujeres en varias direcciones y el carácter dinámico de los intercambios entre las propias mujeres, mujeres y hombres, e incluso, evocar las asociaciones de estas dinámicas propiamente femeninas como política. ${ }^{6}$ Las feministas africanas se concentran en la experiencia de las mujeres africanas y resaltan las diferentes formas de opresión a las cuales estas mujeres están sujetas bajo otra óptica. El esfuerzo aquí no es de categorizar o clasificar las obras de las feministas africanas, sino analizar algunas implicaciones teóricas que el uso del término acarrea.

7 Según Maria do Céu Carmo Reis (1987), fue sobre todo en el siglo XIX, que las mujeres pertenecientes a la sociedad criolla desempeñaron un papel activo en el marco de redes ideológicas primarias como la familia, grupos de alianza, asociaciones de solidaridad, etc. De la profusión de esas prácticas, emergerán las figuras simbólicas, ricas de significados, de las mujeres abastecedoras, fundadoras, conspiradoras, aquellas que armonizaron los ciclos de vida y ritualizaron los intercambios humanos.

${ }^{8}$ Sobre la cuestión de la mujer en la Historia de la Angola pre colonial, existen estudios recientes de las investigadoras brasileñas Renata Costa (2014) y Vanessa dos Santos Oliveira (2018), remontándose a finales del siglo XIX y principios del siglo XX. Centrándose en el siglo XVIII, las investigaciones de la historiadora brasileña Selma Pantoja (2004) y del historiador canadiense José Curto (2016) también deben ser consideradas.

A lo largo del tiempo, es la bibliografía la que va expandiendo el conocimiento sobre este periodo específico de la Historia de Angola, a pesar de que las lagunas todavía sean inmensas.
} 


\section{Mujeres angoleñas en la lucha anticolonial: historiografía, fuentes y memoria}

imaginarlas, puesto que aún sabemos muy poco sobre la posición de las mujeres en Angola pre colonial.

Durante el siglo XX, como destaca la socióloga senegalesa Fatou Sow (2017), las luchas anticoloniales orientaron a las mujeres en dirección a intereses más ligados a cuestiones políticas que a la pauta feminista de lucha contra el patriarcado. Algunas de ellas eran militantes de los movimientos de liberación y en la lucha armada reaccionaron contra la opresión del poder colonial. Como miembras partidarias difícilmente criticaron el poder patriarcal encarnado en los líderes de la independencia, tales como Agostinho Neto, Lúcio Lara, Jonas Savimbi, Holden Roberto y otros.

De acuerdo con Sow, la postura de esas mujeres era de rechazo a los feminismos euroestadounidenses dado que poco hablaban de sus vivencias y de los sistemas de jerarquía diferentes a los suyos. Tras el periodo de lucha armada, entre los años 1960 y 1975, y de las evaluaciones críticas resultantes del proceso de independencia, se abrió progresivamente un espacio más amplio para el pensamiento feminista en la sociedad en general, aquel que situaba el debate de género en y a partir de cuestiones y experiencias del continente africano.

Las noticias de los periódicos consultados para la realización de la investigación de doctorado inicialmente mencionada, reflejan la incidencia de ese pensamiento localizado de reivindicaciones situadas, principalmente después del 24 de abril de 1974, momento en que el autoritarismo y la censura portuguesa supuestamente dejaron de existir en la prensa angoleña.

El artículo publicado en el periódico Diário de Luanda, del 4 de julio de 1975, da muestras de ese movimiento de mayor apertura política al/a los pensamiento (s) feminista (s) africano (s). En la sección titulada: "Actualidad africana" se reclamaba el cúmulo de funciones económicas y sociales ejecutadas por las mujeres africanas. El texto, resultado de la elaboración del Documento de la Comisión Económica para África (CEA), versa sobre el papel de las mujeres en la valorización del continente africano. Postula: "la sociedad africana continúa siendo esencialmente tradicional y los sectores de la economía se asientan en gran parte en las mujeres. Sin embargo, esto no se reconoce". 9

Se presentan datos estadísticos, considerando la fecha de publicación del texto, en los que se afirma que del $60 \%$ al $80 \%$ de los trabajos agrícolas en África eran realizados por mujeres, más del $80 \%$ de los pequeños comerciantes también eran mujeres y más del $50 \%$ del trabajo efectuado en el desarrollo de trabajos comunitarios (construcción de carreteras, escuelas maternales y primarias y centros de aldea) también eran confiados a las mujeres ${ }^{10}$.

El artículo referido enfatizaba el poder de las familias numerosas en gran parte de África, que más allá de engendrar hijos, confería a la mujer africana un cierto prestigio social. No obstante, ni por las condiciones de embarazo, parto y lactancia,

${ }^{9}$ Diário de Luanda. 4 de julio de 1975.

${ }^{10}$ Diário de Luanda. 4 de julio de 1975. 


\section{Dayane Augusta Santos da Silva}

las africanas dejaban de trabajar en los campos o en el mercado. Es decir, el texto identificaba que la mentalidad y opiniones concernientes al papel de la mujer en las sociedades africanas estaban profundamente marcadas por la tradición. La publicación cita ejemplos de la situación de las mujeres en Marruecos, Zambia, Sierra Leona, Etiopía, Sudáfrica, Senegal y Costa de Marfil, Liberia, Gana y Nigeria, con el objetivo de defender la idea de que la emancipación de las africanas tendría que ser a escala continental.

Sin autoría individualizada, estas indagaciones provenían de grupos de mujeres emergentes, jóvenes, pensadoras, lideresas colaborativas, que no se declaraban abiertamente feministas, pero con pautas informadoras de ese movimiento y habiendo protagonizado, algunas de ellas, la lucha de liberación. Como se refirió anteriormente, se trata de cuestionamientos que posibilitaron una apertura para considerar a las mujeres como sujetos históricos.

A pesar de eso, las narrativas acerca de la lucha contra la colonización han sido construidas en masculino y las mujeres han ocupado un espacio periférico, lo que sugiere la continuidad de las formas coloniales de poder en la política interna angoleña. Y aunque las angoleñas participaron efectivamente en la guerra -sin llegar a ocupar puestos de mando-, no fueron reconocidas como actoras en la historia nacional de liberación, salvo en el caso de los mitos nacionales construidos por la historia oficial del país.

En consonancia con Maria Paula Meneses (2017), investigadora del Centro de Estudios Sociales de la Universidad de Coímbra, por historia oficial entiendo la narrativa hegemónica y política construida en el imaginario nacional colectivo, que ha omitido de forma consciente la participación de otras organizaciones y sujetos en la lucha por la independencia. Así, la historia oficial refleja una opción política tomada por un determinado grupo y no considera memorias e historias subalternizadas. Recurriendo al caso de Mozambique, donde existe un mayor volumen de publicaciones sobre las mujeres en la lucha de liberación, y a recortes recientes de la historia de Angola donde los movimientos de mujeres son mucho más plurales e independientes de la supervisión del poder instituido, Meneses busca problematizar otras versiones de la historia de lucha anticolonial. Cita por ejemplo, el caso de Joana Semião en Mozambique, importante estratega política que usó ingeniosamente los recursos asociados a su condición puestos a disposición por el régimen (derecho, educación, etc.) para consolidar su posición y, paralelamente, desafiar el sistema que la representaba como subordinada.

Según la investigadora, la historia de la participación política de mujeres en las luchas nacionalistas, como es el caso de Semião, revela los antagonismos y tensiones que permearon este periodo. Además de incluir a las mujeres en la Historia, se trata de "cuestionar y desafiar la propia idea de historia 'oficial' y problematizar la dicotomía entre lo personal y lo político, entre lo 'oficial' y las historias que se intentan silenciar" (Meneses, 2017, 75).

En la etapa pos independiente mujeres como Muthoni Wa Kirima (Kenia), Deolinda Rodrigues (Angola), Titina Ernestina Silá (Guinea-Bissau), Josina Muthemba Machel 


\section{Mujeres angoleñas en la lucha anticolonial: historiografía, fuentes y memoria}

(Mozambique) se convirtieron en referencias femeninas nacionales por sus participaciones en la lucha armada. Esta es una experiencia compartida por muchos países del continente africano, en su amplio proceso de luchas anticoloniales.

En Angola, las guerrilleras que murieron en los campos de batalla defendiendo sus causas, como es el caso de Deolinda Rodrigues, Irene Cohen, Egrácia dos Santos, Lucrécia Paim y Teresa Afonso, fueron vanguardistas, asentando sus bases en un ámbito, que en principio era predominantemente masculino y desafiando la estructura patriarcal tradicional, ocupando espacios que fueron negados a la mayoría de las angoleñas. Las cinco guerrilleras citadas fueron partidarias del Movimiento Popular de Liberación de Angola (MPLA), tuvieron conexión directa con la Organización de las Mujeres Angoleñas (OMA) y, por lo tanto, sus historias fueron rememoradas.

En los libros de historia, en los carteles y monumentos erigidos en el país, las imágenes y nombres de estas guerrilleras representan la personificación del mito de la heroína en Angola. El monumento en su homenaje, situado en una de las principales calles de Luanda, la avenida Ho-Chi-Min, es una de las expresiones de tales personificaciones. En la escultura, las guerrilleras cargan un libro, una azada y un arma, símbolos construidos por el MPLA y una de las banderas de la lucha anticolonial. Son los rostros de la memoria oficial y del ejemplo revolucionario; pero también imágenes que impiden que sus observadores conozcan otras memorias y protagonistas de esa historia. Es decir, al mismo tiempo que promueven las memorias de unas, propagan una política de olvido desde el punto de vista oficial. La escritura de la Historia de Angola es parte de ese proceso y, con respecto a la historiografía que trata del periodo colonial, todavía queda mucho por hacer.

En la perspectiva de Paul Zeleza, historiador malauí y crítico literario, esto es parte de una larga tradición intelectual que invisibiliza y marginaliza a propósito las discusiones de género en la historiografía africana, pero no solo eso. Para el autor, esa fijación en celebrar y establecer mitos históricos, recuperando y glorificando los grandes estados, ciudades de África y líderes, no solo consumió la energía de los historiadores, sino que también los cegó para los análisis de género.

Las perspectivas son predominantemente androcéntricas y sexistas con un lenguaje que menosprecia y trata con negligencia las actividades y experiencias de las mujeres. $Y$ en el caso de los estudios históricos, que tratan de temas regionales y/o específicos, esto no cambia. Algunos las ignoran por completo, otros las mencionan solo de pasada. El historiador describe una larga lista de textos utilizados en la comprensión de los diversos aspectos de los diferentes países del continente africano que subestiman a las mujeres y además demuestra los problemas que esto trae aparejado (Zeleza, 1997, 21). La marginación de las mujeres también se manifiesta en el contenido y la bibliografía. Las publicaciones sobre mujeres africanas reciben pocos párrafos en el conjunto de las obras.

Entonces, esa historiografía considerada por Zeleza como "nacionalista" fue un proyecto emancipatorio que devolvió a África y a los africanos su historia, mientras que, al mismo tiempo, los excluía. Incluso así, la historia de las mujeres fue ganando 


\section{Dayane Augusta Santos da Silva}

expresión gradualmente. Para el historiador, las investigaciones que involucran a la categoría género todavía están, en gran parte, en la etapa de recuperación de las mujeres en la historia africana, enfatizando su contribución, experiencias, actuaciones, narrativas, en detrimento de la escritura de la historia del género en sí.11 Se trata del desafío de llevar esas narrativas a la escena pública, complejizándolas y demostrando sus ambigüedades, diferencias y desigualdades.

La mayor parte del trabajo crítico de revisión historiográfica viene siendo realizado por diferentes investigadorxs, prioritariamente investigadoras interesadas en la crítica de los prejuicios y distorsiones de cada campo en el estudio de las mujeres desde una perspectiva multidisciplinar. Para ello, hacen uso de una variedad de enfoques, métodos y técnicas, con el fin de recuperar las experiencias y voces de las mujeres.

Según el autor, además de comprender la historia política y las grandes élites africanas, se trata de recuperar las historias sobre las "masas", sean hombres o mujeres, la historia social y económica; analizar la explotación y la opresión, no sólo en referencia al colonialismo, sino llevar a cabo un movimiento doble de revisión de la historia y la historiografía, en la demarcación de un posicionamiento contra la esencialización y universalización de las experiencias.

\section{El debate de género en la historiografía de/y sobre Angola}

En Angola, en el campo de la Historia de las mujeres, la perspectiva crítica de la escritura, sea sobre o hecha por mujeres es reciente. La primera iniciativa en el sentido de realizar una discusión historiográfica sobre la participación de las mujeres en el proceso de lucha contra el régimen colonial, fue de la investigadora Maria do Céu Carmo Reis.

En el artículo pionero, publicado en 1987 en la Revista do Centro de Estudos africanos da USP, titulado "Representation sociale de la femme dans le discours nationaliste: le cas de la géneration des annees 50 en Angola" (Representación social de la mujer en el discurso nacionalista: el caso de la generación de los años cincuenta en Angola), Carmo Reis demuestra de qué manera fue posible discernir el paradigma de representación social de la mujer en Angola a partir de historias y situaciones sociológicas específicas durante la década de 1950 e inicio de los sesenta.

Carmo Reis narra que, en las prácticas culturales de los años 50, en ese momento de ebullición y emergencia del pensamiento protonacionalista angoleño, de legitimidad de una élite africana con vocación intelectual, la mujer no era percibida como un sujeto histórico. En el pensamiento de la investigadora, la representación de la

\footnotetext{
11 Zeleza apunta que las historiadoras feministas tienen una agenda doble acerca de la necesidad de escribir la historia de las mujeres y la historia del género. La historia de las mujeres, como se afirma en el cuerpo del texto, se dedica a las experiencias, actividades y discursos femeninos. Sin embargo, la historia de género proporciona análisis sobre cómo opera esta categoría por medio de una cultura específica. Para el autor, ambos dominios son complementarios y deben reforzarse mutuamente (Zeleza, 1997, 30-31).
} 


\section{Mujeres angoleñas en la lucha anticolonial: historiografía, fuentes y memoria}

mujer estaría inscripta en los discursos nacionalistas de forma difusa y circunstancial. La dimensión femenina no era un criterio. Fue solamente a partir del periodo que va de mediados de los cincuenta a inicio de los años sesenta, que la representación de la mujer, en la perspectiva de la autora, toma forma asumiendo contornos más determinados.

En el contexto de los acontecimientos que marcaron la historia de Angola las revueltas del 4 de febrero y del 15 de marzo de 1961 y las manifestaciones de los nacionalistas organizados en el escenario internacional, en el interior del Movimiento Popular de Liberación de Angola (MPLA) se formaron los primeros "corpus" de textos políticos, propaganda, entrevistas, periódicos, orientaciones generales de las primeras estructuras organizacionales del movimiento, elaborados por muchos de los actores del Movimiento Literario-Cultural de los años 50, como Viriato da Cruz, Mário de Andrade y Agostinho Neto.

En este núcleo dirigente del MPLA, formado por hombres, las mujeres van integrándose lentamente como "militantes", desarrollando papeles adicionales, es verdad, pero también como una fuerza de apoyo moral y a veces material, liberándose de los sufrimientos cotidianos, lo que les permitirá gestionar mejor los asuntos nacionales. Aunque de acuerdo a la autora, para muchas de esas mujeres la consciencia política fue gregaria debido al papel que desempeñaban en la familia y estaba teñida de afectividad al "acompañar" al novio o al marido.

Maria do Céu Carmos Reis, explica que las mujeres sufrieron cruelmente por el declive de las familias criollas $^{12}$ a partir de mediados del siglo XIX (acentuándose este proceso a inicios del siglo $\mathrm{XX}$ ) a causa de las medidas económicas y políticas destinadas a consolidar el poder colonial. Éstas se sumaron a la dictadura de Salazar, iniciada en 1920 y a la acelerada política de colonización después de la Segunda Guerra Mundial. Todos esos cambios, trajeron como consecuencia la pérdida del poder económico de estas familias y, por ende, de estatus social; la restricción de las mujeres al espacio de convivencia familiar, donde desempeñaban el papel de madre y guardiana del hogar; dificultades en el acceso a la educación, etc.

De este modo, según Carmo Reis, no resulta extraña la ausencia de las mujeres en términos de su participación en las discusiones políticas de 1961. Y cuando la hubo, aunque se tratara de un periodo de gran efervescencia política, las referencias eran en relación a su condición de madre y esposa, temas conectados a la regulación de

\footnotetext{
${ }^{12}$ Criolla fue la élite angoleña que hasta mediados del siglo XIX participó del tráfico de esclavos y a lo largo de los años, en su posición de intermediaria, integró también los órganos administrativos y militares en la colonia, además de la Iglesia Católica y sus hermandades. La disgregación de las elites criollas se dio con la cada vez más frecuente presencia de colonos recién llegados de Portugal y la emergencia de una élite asimilada de piel más clara y procedente de la costa. Los factores raciales y regionales fueron usados como armas para deteriorar las relaciones entre esas élites criollas y los nuevos asimilados. A pesar de eso e incluso con su declive socioeconómico, en estas élites continuaba presente: 1) la consciencia de su historicidad y la memoria de una época en que disponían de puestos importantes; 2) la memoria del tiempo en que poseían recursos económicos; 3) la posición que mantuvieron antes de intensificarse la penetración colonial portuguesa a partir de finales del siglo XIX. (Bittencourt, 2002, 33)
} 


\section{Dayane Augusta Santos da Silva}

los problemas cotidianos, de constitución de diferentes cuerpos políticos, formulaciones de estrategias.

Es de ese conglomerado que comienza a emerger una cierta representación de la mujer en el programa principal del MPLA, que define los objetivos generales de la lucha anticolonial y otorga a las mujeres un papel como categoría específica. En el pensamiento de la investigadora, la Organización de la Mujer Angoleña (OMA) surge como respuesta a la necesidad de preparar a las mujeres angoleñas para la lucha de liberación, definida como la participación en los bosques, la preparación de la comida para los guerrilleros, su desempeño como mensajeras, etc. En las palabras de la autora, "pour cimenter cette action, le mot d'ordre adressé spécialement aux femmes et riche de la charge émotionnelle, fait son apparition: "Unies nous Vincrons" ${ }^{13}$

La investigadora presenta un mapa de los elementos que contribuyeron a la tesitura de una representación social de la mujer angoleña como entidad específica organizada cuya existencia solo puede ser comprendida en su contexto y en el juego de otras categorías necesarias al entendimiento de la ideología nacionalista. Reis explica que la división sexual del trabajo concederá a la mujer el papel de ayudar a los guerrilleros en la realización de su objetivo político-militar, principalmente como "cuidadoras de los guerrilleros" y "proveedoras de la guerrilla"; "ella deviendra Femme-Peuple"14.

Según la investigadora, la lucha anticolonial permitirá a la mujer convertirse en sujeto, "mujer-persona" y esa representación le dará una identidad, una conciencia de pertenencia y también una diferencia. Además de eso, le otorgará legitimidad, la fuerza que la libera como pueblo y específicamente como mujer. Para la autora, "être femme-peuple c'est qualifier la femme de telle sorte que sa situation de femme, étant subsidiaire, ne peut apparaître presque sans qualité"15.

En otras palabras, es una representación que ofrece la substancia necesaria para alimentar a la guerrilla, en la que las viejas formas simbólicas, disfrazadas de la mujer-proveedora reaparecen enriquecidas con la grandeza del celo por el "héroe"; pariendo, haciendo existir el "nuevo hombre" y en cierto sentido, participando de la fundación de ese nuevo orden humano en Angola por medio de la lucha por el cambio social.

La publicación del artículo referido es de 1987. Maria do Céu Carmo Reis fue responsable del Departamento de Información y Propaganda y participó en el Departamento de Educación y Cultura del MPLA. Fue incluso objeto de persecución de la PIDE (Policía Internacional de Defensa del Estado) y fue enjuiciada. Es desde

\footnotetext{
13“... para cimentar esta acción, la palabra de orden dirigida especialmente a las mujeres y rica en carga emocional, hace su aparición: "Unidas venceremos".

14 "Ella será mujer-pueblo".

15 “... ser mujer-pueblo es calificar a la mujer de tal manera que su condición de mujer, siendo subsidiaria, no puede aparecer casi sin calidad".
} 


\section{Mujeres angoleñas en la lucha anticolonial: historiografía, fuentes y memoria}

los años de lucha anticolonial que esta autora reflexiona sobre la participación de las mujeres en la guerrilla ${ }^{16}$.

Carmo Reis critica los condicionantes y las limitaciones resultantes de la condición del ser social femenino en la sociedad angoleña. A pesar de los límites, busca reconstruir e historizar, a partir de los discursos nacionalistas, ciertas representaciones de la mujer en Angola. El enfoque de la estudiosa tiene en cuenta el espacio urbano específico de Luanda y un tiempo concreto que no es el de la totalidad del proceso nacionalista. En sus argumentos enfatiza que si bien la posición de las mujeres declinó en el periodo anterior a 1961 debido a las políticas de esa colonización tardía, incluso así, ellas llevaron a cabo iniciativas que remodelaron sus vidas y las representaciones sociales vigentes desafiando el orden hasta entonces establecido.

Otra iniciativa respecto al modo de organizar fuentes y bibliografía, en el sentido de comprender de qué formas las mujeres angoleñas se insertaron en la lucha anticolonial, viene de la mano de la historiadora Maria da Conceição Neto y de la antropóloga Nicásia Matias, a pesar de que tales investigaciones no han sido todavía publicadas (Paredes, 2015, 61)

En el libro Combater duas vezes - mulheres na luta armada em Angola (Combatir dos veces. Mujeres en la lucha armada en Angola), Margarida Paredes relata que esa iniciativa fue del Gabinete de Estudios y Proyectos de la OMA que en 1990 encomendó la investigación al Ministerio de Cultura de Angola, nombrando como responsables a ambas profesoras. De esta iniciativa surgió la ponencia titulada "História da OMA e da Participação da Mulher Angolana na Luta de Libertação Nacional: Considerações acerca da Experiência" (Historia de la OMA y de la participación de la mujer angoleña en la lucha de liberación nacional), presentada en el IV Congreso Luso-Afro-Brasileño de Ciencias Sociales en septiembre de 1996, en la UFRJ, Río de Janeiro. ${ }^{17}$

Publicado en 2008 en Luanda, O livro da paz da mulher angolana - as heroínas sem nome (El libro de la paz de la mujer angoleña. Las heroínas sin nombre), coordinado por Dya Kassembe y Paulina Chiziane (2008), es otro emprendimiento que conformó un equipo multidisciplinar de 18 personas de diferentes nacionalidades Angola, Mozambique y Noruega- reuniendo un conjunto de testimonios sobre varios aspectos de la vida cotidiana de mujeres de diferentes áreas rurales de Angola.

Es un libro de memorias femeninas que parte del registro de la insatisfacción de las mujeres por su limitada participación en los diferentes procesos de negociación de la paz en Angola. Durante la recopilación de informaciones, las entrevistadoras se quedaron sorprendidas pues al tratar de hablar de la paz, las mujeres primero hablaban de las guerras (Kassembe y Chiziane, 2008, 14). En la perspectiva de las

\footnotetext{
${ }^{16}$ La referida investigadora viene reflexionando al respecto desde los años de guerra. De 1974, en el periódico Semanário de Opinião e Informação, encontré el texto de Maria do Céu Carmo Reis que versa sobre la mujer angoleña en la revolución y en la lucha por la emancipación de las mujeres. Semanário de Opinião e Informação. № 11, 21-27 de diciembre de 1974.

17 Desafortunadamente la copia todavía no se encuentra disponible en internet.
} 


\section{Dayane Augusta Santos da Silva}

autoras, es el "grito de millares y millares de mujeres angoleñas a quienes les hubiera gustado contar con la oportunidad de decir algo, de ser escuchadas, de poder explicar sus anhelos y la voluntad de construir una nueva nación" (Kassembe y Chiziane, 2008, 15).

Las historias contenidas en el libro configuran un poderoso arsenal de investigación y el descubrimiento de cómo mujeres comunes, de diferentes áreas geográficas de Angola, reaccionaron ante los desafíos impuestos por las guerras. Esas mujeres, al recordar sus experiencias subjetivas, posicionaron cuestiones sensibles, que muchas veces incluían recuerdos traumáticos de lo que habían vivido en la lucha como guerrilleras.

Este conjunto de relatos escritos en base a testimonios orales posibilita una mirada de las relaciones sociales en el periodo del colonialismo tardío angoleño, donde se pueden observar indicios de las interacciones en las formas de relacionarse, de percibir, comunicar, celebrar, convivir.

Tal proyecto se inscribió en la memoria e historia de Angola, en narrativas no tradicionales de participación en la guerra, en los discursos de las heroínas sin nombre, en los relatos al margen de las descripciones dominantes de participación en la historia de la lucha anticolonial. El libro permite otras interpretaciones de lo cotidiano durante guerra y además cuestiona las representaciones de las mujeres comunes, supuestamente "remolcadas" por los movimientos de liberación.

En Luanda, otro esfuerzo embrionario respecto de dicho tema, viene de la mano del historiador del Instituto Superior Politécnico Tocoísta/ISPT, Patrício Batsîkama18. En el artículo de 2016, titulado "A mulher na luta de libertação e na construção do Estado-Nação" (La mujer en la lucha de liberación y en la construcción del EstadoNación), publicado en el dossier "Áfricas" de la Revista Cantareira, el investigador escribe sobre la participación de las mujeres en las Fuerzas Armadas, en la administración pública y en el aparato del Estado, abordando el caso específico de Luzia Inglês Van-Dunem, primera Generala de las FAA en la reserva y ex secretaria de la OMA/MPLA ${ }^{19}$.

En el texto Batsîkama señala que, a pesar de la multiplicación de voces femeninas en los espacios públicos, en las redes sociales y en las plataformas de discusión, su crecimiento todavía es tímido en la academia angoleña. El historiador afirma que existen discusiones sobre el tema de la participación de las mujeres en la lucha de

\footnotetext{
18 Es también de Batsîkama el reciente artículo de 2020 publicado en la Revista Áfricas, sobre Deolinda Rodrigues, titulado "O poder no feminino. Caso da Deolinda Rodrigues, 'Langidila"' (El poder en el femenino. El caso de Deolinda Rodrigues "Langidila"). El texto es un elogio a la figura de la guerrillera. En la perspectiva del autor, Deolinda reunió todos los presupuestos para ser integrada al "panteón angoleño de los héroes nacionales". Como tal, fue condecorada con la Orden de la Independencia, 1음 grado, por el presidente de la República João Lourenço (en 2019). Reclama su lugar de "casi-fundadora" del MPLA y busca demostrar el carácter de la construcción social de la exclusión de género en Angola. Por motivos ya esbozados a lo largo del artículo, no me detendré en tal publicación (Batsîkama, 2020). El texto es de fácil acceso en internet.

${ }^{19}$ Luzia Inglês es hija de Guilherme Pereira Inglês, quien lideró actos políticos subversivos entre 1957 у 1960.
} 


\section{Mujeres angoleñas en la lucha anticolonial: historiografía, fuentes y memoria}

liberación de Angola, aunque no "orquestada con pompa como tal vez a algunos les gustaría” (Batsîkama, 2016, 75).

Este es un artículo que parte de una perspectiva tradicional, en la medida en que continúa vinculando esa participación a casos excepcionales, como el de la figura histórica de Deolinda Rodrigues. El historiador opta por enfatizar la historia de Luzia Inglês Van-Dúnem, por su peculiaridad, "rica y típica de la mujer guerrera angoleña" (Batsîkama, 2016, 73), no cita nombres de mujeres de otros movimientos que hayan tomado las armas (concretas y simbólicas) para alcanzar la liberación de Angola, o que no tengan el estatus y graduación de Luzia Inglês, como agente civil y militar.

Al realzar aspectos importantes que confieren a Van-Dunem cierta distinción, Batsîkama afirma que sus orígenes "hubieran sido un motivo para su elegibilidad, a pesar de poner en evidencia su trayectoria", y que su aceptación en la lucha no "puede ser vista como un favor machista, sino por mérito" (Batsîkama, 2016, 80). Completa el autor:

Hija de un pastor intelectual, la joven Luzia Inglês tuvo noción de la importancia del know-how, la tecnicidad profesional o la académica y las "ideologías anticoloniales" para alcanzar la independencia. (...) es la misma postura que tomó en el liderazgo de la Organización de la Mujer Angoleña, aunque los contextos hayan cambiado. Durante toda la lucha de liberación, ella desempeñó funciones militares. (...) El presidente del MPLA conocía a su padre y la historia social del "capitán" Inglês, en la instalación de la Iglesia Metodista en Angola, y eso nos parece -en nuestra humilde opinión- una razón sensata (Batsîkama, 2016, 82).

Según el autor, durante mucho tiempo, Luzia Inglês tuvo la "responsabilidad de trabajar en las políticas de inserción de la representatividad femenina y la reestructuración de la familia angoleña", pues "entre varios problemas identificados, se notaba la pobreza simbólica de la mujer", fuese académica, política, financiera o económica (Batsîkama, 2016, 84-85). Los frutos de esta participación surgieron en la creación del "Nuevo Código de Familia, del Ministerio de la Familia y Promoción de la Mujer, en la Constitución de Angola de 2010." (Batsîkama, 2016, 72).

Para Batsîkama, la necesidad de revalorizar a la mujer angoleña se justificaba incluso con base en los datos del reporte del PNUD de 1997, en el alto índice de analfabetismo entre las mujeres -un 75\%, mientras que el de los hombres era de 24\%-, lo que las convertía supuestamente en "más vulnerables", por no ser alfabetizadas. En palabras del historiador:

La cultura representa simbólicamente el valor sociohistórico de un pueblo, de manera que utilizar esa teoría, en la institución del estado-nación es importante para eliminar la pobreza simbólica que existe entre diferentes 'grupos' representativos que ocupan el territorio. En ese aspecto, el fortalecimiento de la mujer es una opción, puesto que justamente es resultado del propio mérito (Batsîkama, 2016, 86). 


\section{Dayane Augusta Santos da Silva}

El autor referido da a entender, por ejemplo, que tener escolaridad y ocupar altos cargos es una cuestión de "opción" y mérito individual de la mujer. Y esto, ya sabemos que es cuestionable, dado que el acceso a la educación y a los espacios de poder en Angola es una cuestión social y política estructural del sistema patriarcal. Las mujeres se encuentran excluidas del derecho a la educación y a espacios de poder. Además, una mujer "empoderada" no necesariamente ocupa posiciones de poder en la sociedad, ni tiene total libertad en el ejercicio de su función. ${ }^{20}$

Es evidente que en este artículo, aunque no sea especialista en el asunto, el autor escribe con vistas a valorar la presencia de la Mujer en la lucha de liberación de Angola dándole visibilidad al tema a partir de un caso ejemplar. Sin embargo, a lo largo del texto, continúa preso de la idea de la mujer como "educadora primaria de las/os niñas/os", "epicentro de la cohesión familiar", "madre que transmite los valores", "centro de la estabilidad entre varias familias y clanes" etc. El historiador no aborda las diferentes y múltiples formas de participación de las mujeres, más allá del papel tradicional asociado a su género como dimensión rígida, estática y congelada.

En términos historiográficos se percibe un movimiento endógeno de investigadores e investigadoras angoleñas y angoleños en el análisis de temas de recopilación y producción de fuentes y bibliografía conectados a la historia de las mujeres y, al mismo tiempo, se da la formulación de un campo de estudios. Estos investigadores e investigadoras buscan responder sus propios interrogantes y conocer las necesidades tanto intelectuales como materiales de su sociedad.

En Brasil, en el área de Historia, el primer trabajo sobre tal temática se titula Um outro lado da guerra colonial - História de mulheres que participaram da luta pela Libertação de Angola (El otro lado de la guerra colonial. Historia de mujeres que participaron de la lucha por la liberación de Angola (1961-1975) de Daiana Castilho Dias $^{21}$. Esta fue una disertación de maestría presentada en la Universidad de Brasilia en abril de 2002, cuando Luanda todavía vivía al calor de la guerra civil. Castilho Dias realizó investigaciones en los archivos de Lisboa, puesto que en esa época debido a la situación de guerra civil del país "los testimonios directos de las mujeres se convirtieron claramente en poco probables" (Castilho Dias, 2002, 5).

En la tentativa de buscar otros relatos que no fueran de ex guerrilleros o líderes de movimientos relacionados a una literatura llamada "panfletaria" que promovía acciones del movimiento de Liberación, Daiana Castilho Dias investigó la historia de mujeres angoleñas en los archivos de la Policía Internacional de Defensa del Estado (PIDE/DGS), localizados en el Archivo Nacional de la Torre del Tombo (ANTT) en Lisboa, Portugal.

\footnotetext{
${ }^{20}$ Considero que en una sociedad desigual, el poder es más una cuestión de privilegio y acceso a recursos, que de cualidades individuales.

${ }^{21}$ Por motivos que desconozco, el trabajo de la autora no fue publicado en internet y no se encuentra disponible en el repositorio institucional de la Universidad de Brasilia. Tuve acceso al material en el banco de tesis y disertaciones impresas del Programa de posgrado en Historia de la Universidad de Brasilia.
} 


\section{Mujeres angoleñas en la lucha anticolonial: historiografía, fuentes y memoria}

Con base en una perspectiva de género, la investigadora examinó más de 200 procesos, individuales y colectivos, con el propósito de "observar, describir y analizar las imágenes de mujeres combatientes, formuladas por sus compañeros de lucha, por las organizaciones en las que participaban y por la política represiva del Estado" (Castilho Dias, 2002, 7).

Castilho Dias identificó que estas mujeres eran vistas como "putas comunistas", "compañeras de lucha" y/o "madres protectoras y cuidadoras"; todas ellas personificadas en la figura de la "mujer combatiente". En la definición de Margarida Paredes $(2015,34)$, una ex-combatiente es aquella mujer que participó en una guerra con arma en mano y sobrevivió al conflicto. Completa Daiana Castilho Dias:

(...) tres imágenes diferentes fueron atribuidas a esas mujeres: los colonialistas las trataban como las "prostitutas, analfabetas y terroristas", mientras que los Movimientos de liberación intentaban transformarlas en "Diosas protectoras, guardianas del futuro de la Nación que estaba por surgir". Los compañeros de lucha vivían en constante conflicto, pues debían "admitir" la presencia de mujeres en las milicias sin verlas sexualmente y todavía más, intentando transformarlas en "verdaderos hombres", sin olvidar, no obstante, que eran el "sexo débil" y que de ninguna manera significaban algún tipo de competencia a su dominación (Castilho Dias, 2002, 121).

Según la autora, estas imágenes impregnaron e influenciaron de tal manera a la sociedad que es posible percibir por medio de la documentación, que las propias mujeres asumían comportamientos diferenciados durante la guerra de liberación, adoptando aquellos semejantes a los dichos masculinos o masculinizantes, como por ejemplo en el uso de su indumentaria de guerra.

Esta es una investigación valiosa desde el punto de vista de la deconstrucción de estereotipos y de la discusión de la demarcación de espacios entre hombres y mujeres en la guerrilla. La relación establecida entre la represión del régimen colonial entre hombres y mujeres nacionalistas está atravesada por estructuras de poder y, por ende, éstas deben ser estudiadas.

Sin embargo, bajo la idea de dar visibilidad y deconstruir la pluralidad de imágenes negativas de la mujer guerrillera, Castilho Dias explora poco el papel de las mujeres que desafiaron ese lugar común, puesto que las mujeres enfrentaron los estereotipos como espías, informantes, instaladoras de bombas, estando presentes o no en la dirigencia de organizaciones. Aunque de modo diferente a como lo plantea Batsîkama, la autora muestra relatos de mujeres hablando por sí mismas y actuando como sujetos de su propia historia, aún cuando hombres y mujeres estuvieron unidos en la búsqueda de un objetivo común y tales diferencias, a priori, no pudieron aparecer.

En relación a esto, en el texto Biografia, memórias coloniais e legados pós-coloniais (Biografía, memorias coloniales y legados poscoloniales), Margarida Paredes apunta que las africanas sufrían doble marginalidad, como mujeres y colonizadas. Para la autora, ambas condiciones de marginalidad llevaron a las mujeres a explorar nuevas formas de lucha y solidaridad, "porque los movimientos de liberación subordinaban 


\section{Dayane Augusta Santos da Silva}

la emancipación de las mujeres a la prioridad de la liberación nacional y ellas mismas -las mujeres que lucharon en las guerras anticoloniales- no se identificaban como feministas" (Paredes, 2017, 405).

En ese sentido, a primera vista, parece que no hubo un diálogo entre la participación de esas mujeres en los movimientos de liberación y en la lucha feminista, pese a que las ideas de resistencia y enfrentamiento estuvieran presentes como prácticas.

En el tercer capítulo de la disertación de Daiana, la investigadora destaca las historias de vida de guerrilleras renombradas, Deolinda Rodrigues e Irene Cohen y evidencia incluso, el caso de la médica Ana Wilson y de la primera presidente de la OMA, Mariana Ana Paz. En el cuarto capítulo, titulado: "Nosso país é onde o coração está!" (¡Nuestro país es donde está el corazón!) Castilho Dias analiza la historia de mujeres como Alda Espirito Santo, Noemia de Sousa y otras, algunas de ellas extranjeras, que lucharon por los mismos ideales de libertad y justicia en la liberación de los países bajo dominio del colonialismo portugués. Son mujeres que fueron "activistas" en varios movimientos y "marcaron no solo la historia de liberación frente al colonialismo portugués en sus países, sino que principalmente, influenciaron y concientizaron a muchas otras mujeres y hombres que soñaban con una condición más humana para el africano" (Castilho Dias, 2002, 105).

A pesar de no haber anexado las transcripciones de las entrevistas que cita a lo largo del texto, la autora suma una recopilación de nombres de activistas en las luchas de liberación que actuaron en el contexto africano y en la clandestinidad, con número de juicio y carpetas contenidas en el sector correspondiente de los archivos de la PIDE, una recopilación que puede ser útil a otros investigadores.

Las luchas de liberación de los países africanos sirvieron como base de formación para la actuación de mujeres en diferentes espacios. Las constantes batallas contra el imperialismo, el colonialismo y el racismo acabaron por demostrar que las mujeres también tienen un campo de actuación, aunque solas no consigan reaccionar contra la red de elementos que las encarcelan en un lugar de sumisión, incluso la historiográfica. Según Castilho Dias, "estas mujeres penetraron un espacio definido por y para los hombres y marcaron presencia en la guerrilla, donde actuaron en las más diversas actividades" (Castilho Dias, 2002, 121), pese a que raramente hayan tenido un papel reconocido como sujetos de la guerra.

En ese sentido, el libro de la antropóloga Margarida Paredes, Combater duas vezes mulheres na luta armada em Angola (Combatir dos veces. Mujeres en la lucha armada en Angola), fruto de las entrevistas que la autora realizó a mujeres que combatieron en diferentes formaciones políticas y militares de Angola como prisioneras de guerra y disidentes, configura un extenso archivo "superior a una centena de entrevistas, que pretenden contribuir a la construcción de memorias en femenino en Angola, para su estudio e interpretación" (Paredes, 2015, 44-46). Explica Paredes:

En el sentido de rescatar el papel histórico y la memoria de la participación de estas mujeres en las luchas de liberación, en los conflictos poscoloniales y en la 


\section{Mujeres angoleñas en la lucha anticolonial: historiografía, fuentes y memoria}

construcción de los nuevos estados-nación, incluso de aquellos que están siendo construidos bajo el signo de exclusiones múltiples, como es el caso de Angola, creé un archivo de memorias de guerra en femenino, dado que estos testimonios no solo permiten salvar lo dicho para las generaciones futuras, sino también descentrar de occidente las grandes narrativas y así revelar las operaciones del imperialismo conceptual, intelectual (...) evidente en las formas del colonialismo y del racismo (Paredes, 2017, 407).

Paredes amplia la investigación de Daiana Castilho Dias, abordando como vivencia, testimonio y resistencia, la participación de las mujeres angoleñas en el periodo de guerras de 1961 a 2002 por medio de narrativas biográficas ancladas en la historia oral. La antropóloga portuguesa y también antigua combatiente de las Fuerzas Armadas Populares de Liberación de Angola (FAPLA/MPLA) desde 1973, defendió su tesis de doctorado en 2014 en el Instituto Universitario de Lisboa (ISCTE-IUL) y la publicó un año después. Margarida Paredes escribe desde la múltiple condición de ex guerrillera, escritora y antropóloga, cruzando su historia de vida con los pensamientos poscolonial y feminista (Paredes, 2017, 397).

Según la investigadora, el libro surgió de la demanda de las propias combatientes angoleñas, que reclamaban la falta de visibilidad y acceso al espacio público como sujetos históricos, "muchas de ellas se quejaban del silenciamiento y del hecho de que los hombres se apropian de la Historia y del protagonismo en ese proceso" (Paredes, 2017, 403). Paredes afirma que, el "deseo de protagonismo evidenciado por las entrevistadas se inscribe también en la conciencia subjetiva que tienen las veteranas de que el reconocimiento de sus luchas contribuirá a aumentar la representatividad política de las mujeres" (Paredes, 2015, 47).

Por tanto, según la autora, la historia de las excombatientes, "sus compañeras de armas", no puede ser estudiada como una categoría monolítica o grupo homogéneo, porque, "como recuerda Jacklyn Cock, estas mujeres tienen edades, niveles educativos, contextos culturales y vivencias personales y políticas muy diversas", de ahí la importancia de las intersecciones de categorías que permean lo racial, social, religioso etc., las cuales operan en el periodo de guerra atravesadas por el género (Paredes, 2017, 34).

Paredes comenta que la Historia con nombre, cuerpo, voz, emoción y esperanza se confronta con la teoría crítica de los estudios subalternos, que plantea a un sujeto femenino silenciado, apagado y/o marginalizado de la Historia y de los discursos hegemónicos. En esa perspectiva y siguiendo a Gayatri Spivak (2010), ella argumenta que las mujeres africanas no han estado en silencio, sino que no han sido escuchadas ni comprendidas, porque "otros/as" han hablado por ellas o en sus nombres. "Este peligro de constituir el "otro" como objeto de conocimiento puede llevar a los intelectuales a intermediar el habla de los "subalternos" y a tener la ilusión de que pueden hablar por ellos" (Paredes, 2015, 50-51).

En esta línea de pensamiento, como dije anteriormente, en la discusión de género propuesta en su investigación de doctorado interesa el lugar de enunciación de las mujeres angoleñas, su agencia y su protagonismo como formas de acción 


\section{Dayane Augusta Santos da Silva}

institucionalizada o no, pese a que "resulte imposible que el "subalterno" sea escuchado sin interpretar los mecanismos de dominación de poder encubiertos por la ideología dominante, por relaciones de poder desiguales" (Paredes, 2015, 51).

La investigación de Margarida Paredes permite comprender las luchas de liberación y la guerra civil debido al sentido presente en las narrativas de las antiguas guerrilleras del Movimiento Popular por la Liberación de Angola (MPLA), así como de las mujeres-soldado de las Fuerzas Armadas Populares de Liberación de Angola (FAPLA) o de las ex combatientes del Frente Nacional por la Liberación de Angola (FNLA) y de la Unión Nacional para la Independencia Total de Angola (UNITA).

Tales relatos nos invitan a revisitar los aspectos contextuales de esos dos periodos: el de la independencia (1960-1975) y el de la guerra civil (1975-2002), abordados como un "único" conjunto por Margarida Paredes, buscando tejer comparaciones, cruzar testimonios y contrastar historias. Considero que desde el punto de vista histórico debe prestarse atención, dado el carácter diferenciado de esos momentos y sus peculiaridades, a pesar de ciertas continuidades en varias experiencias.

La primera guerra ocurrió cuando Angola todavía estaba bajo el mandato del colonialismo portugués y vivía a la sombra del luso-tropicalismo, al mismo tiempo que grandes centros urbanos como Luanda pasaban por un periodo de crecimiento económico e industrial. La segunda guerra estalló cuando abiertamente las élites africanas se disputaban el poder, confrontándose entre sí, lo que no significa que eso no ocurría antes. Fue éste el momento en que hubo un mayor número de muertes, y mayor introducción de arsenal armamentista y la implicación directa de potencias extranjeras en la disputa, etc. Ocasión también en que las angoleñas ya estaban organizadas e insertas en los destacamentos militares de los movimientos de liberación, estructurados efectivamente a partir de 1974. Por todo esto, se trata de dos periodos históricos que deben ser cuidadosamente historizados.

Tanto el trabajo de Daiana Castilho Dias como el de Margarida Paredes utilizan la perspectiva de género para contestar la desigualdad de poder entre hombres y mujeres en Angola. Se trata de la consolidación de mujeres intelectuales mediante investigaciones a un nivel de posgrado en un movimiento que parte de afuera hacia adentro en relación al campo de estudios de historia de las mujeres de Angola. Son trabajos precursores en el tema, que fundan líneas de investigación en el área de género en Brasil y en Portugal, y amplían los enfoques sobre la cuestión en los países de lengua portuguesa. Poco a poco, este tipo de investigaciones renuevan el campo de estudios con otros enfoques, no necesariamente nuevos, pero con perspectivas renovadas para el análisis de cuestiones anteriormente abordadas.

El artículo titulado "Intimating Nationalism: Gender in the MPLA'S maquis" (Nacionalismo íntimo: género en los maquis del MPLA) de la historiadora estadounidense Marissa J. Moorman (2016) suma esfuerzos a la comprensión de las vivencias de las mujeres en la guerra. Publicado en 2016, es un texto que utiliza la experiencia de investigación de un trabajo anterior sobre la música en los musseques 


\section{Mujeres angoleñas en la lucha anticolonial: historiografía, fuentes y memoria}

de Luanda, para posicionar cuestiones de género. ${ }^{22}$ Basándose en las memorias de jóvenes oficiales, en sus descripciones de la vida cotidiana en los campos de lucha, en el profundo aburrimiento de marchar, acampar y esperar, Moorman revela los detalles de la convivencia entre hombres y mujeres, definida también por el género. Para la estudiosa, el tropo de la familia como elemento clave que conecta la nación, continúa siendo una narrativa poderosa de determinación de papeles. Moorman dialoga con la publicación de Margarida Paredes (2010) sobre Deolinda Rodrigues y la influencia de la familia metodista en el seno de la familia MPLA resultado de una moral y una ética heredadas del puritanismo protestante Lo que induce a ambas investigadoras a pensar que los "dirigentes fueron llevados a reproducir modelos y estándares de esa cultura religiosa en su modus operandi, en el movimiento de liberación" (Paredes, 2010,14). Paredes se arriesga a afirmar que el autoritarismo del MPLA al exterior, erudito y masculino -como la antropóloga lo describe-, puede tener relación con el paternalismo característico de las misiones metodistas.

De acuerdo con Moorman (2016), si bien la familia fue el principio fundamental hegemónico para la comprensión del género y la nación, también podía ser comprendida como un espacio dinámico, en el que las tensiones se manifestaban como alegoría, más que como metonimia para la nación. Es decir, interpretada no como un modelo estancado, sino como un lugar donde el poder opera, no sólo como símbolo.

Para la investigadora, en las familias MPLA y en la familia nacional en formación, las mujeres fueron figuras "ambivalentes", con papeles e imágenes el movimiento buscaba definir. Y aunque patrones retóricos como "padre de la nación", "patria", "hijos de la tierra", estuviesen presentes en las narrativas de nacionalistas angoleños, las mujeres no estuvieron limitadas a seguir el ejemplo de los hombres, al contrario, fueron también una fuerza motora. No estaban menos comprometidas con la lucha por la nación de lo que estaban los hombres, aunque estuviesen situadas de maneras diferenciadas en relación y dentro de la lucha anticolonial.

Según la investigadora, ellas se involucraron en trabajos que desafiaron las nociones existentes de feminidad. En el exilio, por ejemplo, Moorman menciona el caso de aquellas mujeres que aprendieron nuevas habilidades en países del bloque soviético y condujeron camiones, transportaron armas escondidas, actuaron como espías,

22 Marissa J. Moorman ha dedicado sus investigaciones a repensar la nación y el nacionalismo desde el punto de vista de aquellos que no adhirieron a la lucha armada, pero que se definían como nacionalistas. En la perspectiva de la historiadora, en los clubes y fiestas de los musseques de Luanda, en la producción musical en sí, la juventud urbana y los artistas moldearon la base cultural de la nación y, por tanto, se involucraron en el proyecto político del nacionalismo. Distantes de la lucha de guerrilla, esta juventud y artistas fueron de hecho centrales para la nación, produciendo temporalidades y espacios alternativos paralelos a la lucha armada y perpendiculares al proyecto colonial. Según Moorman, la escena musical creó un espacio alternativo donde los participantes percibían una soberanía cultural y construían una autosuficiencia económica, luchando contra el dominio colonial en sus prácticas cotidianas. Para las mujeres, sin embargo, que tenían menor acceso a la educación y al empleo, y cuyas reputaciones eran más dependientes de sus nombres de familia y también de su comportamiento, la música tenía un significado ambivalente. Incluso así, hombres y mujeres angoleñas crearon un capital social y cultural de enfrentamiento, trabando la lucha en varios frentes (Moorman, 2004). 


\section{Dayane Augusta Santos da Silva}

trabajaron en logística y combatieron en la lucha armada en las regiones militares del MPLA. Lo que no solo perturbó las nociones de feminidad prevalecientes en la sociedad angoleña colonial tardía y dominantes en los liderazgos del MPLA, sino que también implicó energía retórica para contener los elementos subversivos de ese trabajo.

La estudiosa afirma que la propaganda que describió la participación de las mujeres buscaba atraer y movilizar a aquellas que todavía no estaban implicadas en la lucha anticolonial como madres, protectoras de la comunidad, esposas, hijas, etc. No obstante, tal retórica fue alternada entre el estatus ambivalente de las mujeres, los contornos mutables de la feminidad y los discursos de quienes producían sus representaciones. La historiadora asume que el MPLA, vía la OMA, en sus pronunciamientos oficiales apoyó la participación de las mujeres en la lucha de liberación, a pesar de que tanto dentro como fuera del movimiento estuviesen bajo la tutela de los hombres.

Moorman explica que existían fuerzas sociales y culturales que restringían inclusive la vida íntima de las mujeres. Dentro de los maquis y/o del movimiento en general, a veces el MPLA asumía funciones de estado, facilitando por ejemplo las uniones entre guerrilleros y guerrilleras. Esas uniones proporcionaban una forma de construcción nacional basada en un modelo revolucionario, pero que continuaba siendo liderado por hombres. Las reglas y restricciones de la vida íntima de las angoleñas y angoleños que participaban de la lucha de liberación buscaban moldear la sexualidad y crear una nueva masculinidad que por el bien de esa nación emergente era sexualmente disciplinada, monógama, estaba educada políticamente y era obediente a los mandos del movimiento.

El trabajo de Moorman acentúa la falta de reconocimiento oficial de las contribuciones femeninas y se centra en las experiencias desde el punto de vista de la historia social, como el ejemplo que presenta de una boda donde el MPLA se convierte en una autoridad propia que sanciona el establecimiento de la familia.

El último trabajo del que tengo conocimiento, como contribución a la discusión de género y lucha de liberación nacional en Angola, es el de la filósofa keniana y doctora en estudios de género y sexualidad por la Universidad de California, Berkeley, Selina Makana (2017).

Con una investigación reciente y habiendo presentado su tesis de doctorado en 2017, Selina Makana explora la compleja relación de las mujeres en las guerras y la militarización. La investigadora narra las múltiples formas en las que las mujeres angoleñas fueron implicadas por esa interacción en los conflictos armados de la independencia (1961-1975) y de la guerra civil (1975-2002) angoleña.

La filósofa comparte el consenso entre las investigadoras anteriormente mencionadas, sobre la invisibilización narrativa de mujeres en la historia nacional de Angola. A pesar del intento, ya señalado por Moorman (2016) de visibilización propagandística y panfletaria de los movimientos, en la concepción de Makana se recurrió a la "implantación del tropo de la maternidad" como incentivo a la 


\section{Mujeres angoleñas en la lucha anticolonial: historiografía, fuentes y memoria}

participación de mujeres en la lucha. Incluso así, el espacio altamente masculinista de la lucha armada contribuyó a la invisibilidad de las combatientes.

En su tesis, Selina Makana tiene el propósito de restaurar la narrativa de mujeres en la historia del nacionalismo angoleño, demostrando que ellas también fueron cocreadoras de esa historia. El descontento anunciado por la propia investigadora es acerca de las representaciones estereotipadas de mujeres africanas en las narrativas de guerra.

La investigadora realizó un trabajo de campo etnográfico que incluyó la realización de entrevistas orales (formales e informales) con veinticinco mujeres, además de investigación en los archivos de Lisboa y revisó reportes de Naciones Unidas, del gobierno angoleño, del MPLA, de ONG's (por ejemplo, Human Rights Watch y Amnesty International), etc. Este estudio atraviesa diferentes espacios geográficos durante el proceso de investigación y escritura.

Según Makana, el género fue principio organizador de la militarización en la sociedad angoleña. En ambas guerras fue organizado, financiado, comercializado, consumido y mantenido. Y a pesar de las restricciones patriarcales dentro de los movimientos nacionalistas, la lucha armada ofreció a las mujeres una oportunidad de representar su agencia como sujetos políticos. Algunas mujeres vieron al servicio militar como una posibilidad de movilidad socioeconómica ascendente.

Esa relación compleja, entre las mujeres, la guerra y su invisibilidad, habría llevado a estudiosos y activistas a defender la idea de que cuantas más mujeres entraran en el mundo del combate, como una oportunidad para alcanzar igualdad de derechos, esto sería liberador en cierto sentido. Según Makana, ser parte de las fuerzas armadas, principalmente después de 1974, año de creación del destacamento femenino armado del MPLA, proporcionaba una oportunidad de expandir las normas de género que inicialmente restringían a las mujeres a papeles no combativos.

Para la investigadora, la entrada de las mujeres en esos espacios tal vez pueda ser vista como una estrategia para desafiar las nociones hiper masculinistas existentes en la época. Los cuerpos de las mujeres soldados exigieron inclusión, transgredieron y socavaron las fronteras que los definieron, a pesar de no haber eliminado o incluso corrompido el poder patriarcal de los movimientos nacionalistas.

La estudiosa argumenta que, si bien las motivaciones de ingreso en las fuerzas armadas fueron diferenciadas, las angoleñas también se unieron a las diferentes instituciones militares porque tenían un fuerte sentido de patriotismo y lealtad para con el país. Otras usaron las guerras para redefinir los modelos de feminidad africana y las ideologías de género que continuaban considerándolas apolíticas.

Makana interpreta los testimonios de las mujeres angoleñas como contra-narrativas que demuestran la agencia y la resiliencia de las mujeres, y nos permiten conocer lo que percibían sobre los roles que desempeñaron en el cuerpo político de la nación. La lucha armada habría ofrecido a las mujeres espacios para escenificar su agencia como sujetos políticos, protagonistas de su propia historia. 


\section{Dayane Augusta Santos da Silva}

En su tesis la investigadora keniana reflexiona sobre la compleja relación entre la maternidad y las revoluciones armadas, ya que ambas cuestiones involucran el nacimiento y el cultivo de una nueva nación. En Angola, en los tres movimientos, MPLA, FNLA y UNITA ${ }^{23}$, el tropo de la maternidad fue herramienta movilizadora de la inclusión de mujeres en la guerra. Mientras tanto, si este "tropo de la maternidad" ofreció a las mujeres una identidad política emancipatoria o no lo hizo, es un debate en curso.

Makana destaca que no basta realzar las contribuciones de las mujeres en las historias nacionales, desconsiderando sus traumas, las formas de violencia inscritas en los cuerpos de las mujeres en tiempos de guerra, los procesos de luto y de volver a comprometerse con la vida, puesto que esa historización del pasado reproduce una memoria colectiva basada en borrones y silencios. De acuerdo con la estudiosa, toda mujer angoleña tiene cicatrices visibles e invisibles derivadas de la guerra (estupros y violencia).

Estas investigaciones enfatizan la pertinencia de recordar la presencia de las mujeres en la historia y cuestionan los lugares a los que fueron tradicionalmente relegadas. Por tanto, consideré conveniente esbozar en trazos generales, un breve recorrido histórico de los estudios de género que asocian a la mujer y la guerra. Los trabajos sobre el papel de las mujeres en las guerras, aunque existen, están muy lejos de lo deseado y todavía queda mucho por hacer. En el exterior, existe una mayor divulgación del papel de las mujeres de la Organización de las Mujeres Angoleñas (OMA), constituida en 1961 (Ferreira, 2018, 54).

En esta discusión historiográfica, como estrategia para incluir los estudios anteriormente mencionados sobre la participación de las mujeres angoleñas en la primera guerra, mapeé las historias de sujetas anónimas, no militarizadas, de las diferentes áreas rurales de Angola, mujeres comunes, principalmente campesinas, que participaron en la cobertura de la retaguardia, en una perspectiva de historias en plural. Faltan elementos sobre la participación de las mujeres de áreas rurales, poco o muy afectadas por la guerra, para un mejor conocimiento del trabajo que desarrollaron las mujeres durante la lucha anticolonial. Tal tema exige una investigación muy profunda.

También contamos en portugués con el artículo de Aurora da Fonseca Ferreira (2018), "La contribución de la mujer en la formación del saber y del conocimiento", publicado en 2018, en la $2^{\text {a }}$ edición de la obra A mulher em África, vozes de uma margem sempre presente (La mujer en África, voces de un margen siempre presente), organizada por las investigadoras Inocência Mata y Laura Cavalcante Padilha, que esboza brevemente el papel de la mujer angoleña en la liberación e independencia del país y en el periodo pos independiente.

\footnotetext{
${ }^{23}$ MPLA - Movimento Popular de Libertação de Angola (Movimiento Popular de Liberación de Angola); FNLA - Frente Nacional pela Libertação de Angola (Frente Nacional por la Liberación de Angola) y UNITA - União Nacional para a Independência Total de Angola (Uniçon Nacional para la Independencia Total de Angola).
} 


\title{
Mujeres angoleñas en la lucha anticolonial: historiografía, fuentes y memoria
}

Ferreira corrobora la idea inicialmente enunciada de que la conquista de los derechos de las mujeres en Angola ganó expresión principalmente con la lucha de liberación. La autora expone que durante ese periodo, el lugar ocupado por las mujeres en la sociedad angoleña, de modo general, fue fruto de sus propias conquistas.

La autora comenta la importancia de la Organización de la Mujer Angoleña (OMA) para la movilización y ampliación de sus bases después de la liberación del yugo colonial. La OMA busca "establecer el papel de la mujer angoleña, políticamente encuadrada o no, en el desarrollo de la lucha de liberación nacional". Sin embargo, la situación de las mujeres en el ámbito de los objetivos de la lucha protagonizada por la Unión por la Liberación Total de Angola (UNITA) o incluso por el Frente Nacional de Liberación de Angola (FNLA) no es discutida, posiblemente debido a la falta de preservación de los archivos de esas instituciones, teniendo en cuenta principalmente el contexto de guerra civil ocurrido en el periodo posterior a la independencia.

Según la investigadora, el largo período después de la independencia puede ser interpretado como un momento de ruptura en el marco del proceso general de lucha por la emancipación, "aunque retomando la "tradición" para la propuesta del análisis tradicional del lugar de la mujer, en el sistema de producción de la relación entre familia y trabajo", situaciones colocadas como formas de opresión y explotación.

Pese a la falta de datos estadísticos, Ferreira sostiene que parece haber sido en la pos independencia que las conquistas de las mujeres ganaron un mayor impulso con el aumento del nivel de formación escolar, posibilidades de matriculación y educación pública y gratuita como impulsoras del nivel escolar de la población femenina. Completa Ferreira:

\begin{abstract}
En conclusión, podemos percibir que fue la preocupación de incentivar un mejor conocimiento del comportamiento de la mujer, su rol, su función y, por consiguiente, comprender su lucha en las sociedades africanas de Angola, lo que nos llevó a mostrar la importancia de las investigaciones sobre las mujeres y las sociedades o comunidades en las que se inscriben. De este modo, pensamos que puede ser posible saber en qué medida la condición de la mujer angoleña (africana) tuvo causas y recorridos idénticos a otros, en diversas partes del continente y del mundo (Ferreira, 2018,65).
\end{abstract}

Conforme a lo que afirma Ermelinda Liberato (2016) en el artículo que traza reflexiones en torno a la condición de la mujer angoleña en los 40 años de independencia, lo que se sabe sobre las condiciones de vida de las angoleñas y en particular sobre su posición en la sociedad (y durante las guerras) es mucho más complejo de lo que los propios documentos nos muestran.

Henda Ducados (2000), en el artículo “Angolan Women's Survival in Times of War in an All-Men's Show" (La supervivencia de las mujeres angoleñas en tiempos de guerra en un espectáculo exclusivamente para hombres), argumenta que la pos 


\title{
Dayane Augusta Santos da Silva
}

independencia tendió a invisibilizar y reforzar estereotipos de género en el ámbito de la política formal pese a que las mujeres habían participado en la lucha de liberación. Ducados explica que los intereses de las ex combatientes rara vez fueron priorizados en situaciones de posguerra, mientras que los varones ex combatientes y sus familiares fueron foco de la reintegración, reforzando el modelo del hombre como sustentador del hogar. La violencia de género y el abuso sufrido por las mujeres durante las guerras también fue desatendido. Para la autora, los intereses de las ex combatientes están en segundo plano en comparación con los de sus colegas varones en la posguerra. Sin derechos, las mujeres se encuentran subordinadas a los intereses del partido marxista que relega a un segundo plano el debate de género. Resume Paredes:

\begin{abstract}
Ducados considera que el machismo arraigado en los valores tradicionales africanos y en las prácticas masculinistas latinas, heredadas de los portugueses, hicieron muy difícil a las mujeres desafiar el funcionamiento de la sociedad angoleña. (...) En el análisis de la OMA, se argumenta que esta organización sufre de las limitaciones comunes a las organizaciones de mujeres en contextos dominados por el partido único marxista, en el que los derechos de las mujeres son subordinados a los intereses del partido, restringiendo la lucha por una agenda de emancipación y fortalecimiento de las mujeres. (Paredes, 2015, 65)
\end{abstract}

Esto significa que el género no fue una problemática central para los movimientos de liberación. Mbembe (2001) ya subrayó que durante el largo proceso de descolonización muchos líderes de la resistencia dudaron entre opciones de principio y alianzas dudosas y siguiendo una línea en zigzag, se situaron en una zona ambigua de incógnita dependencia. Tal inadecuación originó otras estructuras, incluyendo el movimiento de mujeres y el (los) feminismo(s), que en los años 70 conforme fue presentado inicialmente, buscaron comprender clase, género, raza, nacionalidad, tradición, entre otras construcciones sociales en la génesis de la opresión y liberación de las mujeres.

Por tanto, son pocos los trabajos que abordan tal temática, pese a que hoy las mujeres ocupen espacios importantes en el mundo en general y en la sociedad angoleña en particular. Margarida Paredes hace referencia a algunos trabajos escritos en inglés y de poca circulación en los países de lengua portuguesa, los que además no se encuentran en internet. La autora menciona, por ejemplo, la investigación del antropólogo estadounidense Don Barnett y de Roy Harvey (2015), en el libro The Revolucion in Angola: MPLA, Life Histories and Documents (La revolución en Angola: MPLA, historias de vida y documentos), sobre la historia de Marsha, una recluta que se adhiere a la guerrilla a los 14 años siendo la única mujer en un grupo de 90 instructores. Paredes cita una obra publicada en 1984 por la OMA, Angolan Women Building the Future, from National Liberation to Women's Emancipation (Mujeres angoleñas construyendo el futuro, de la liberación nacional a la emancipación de las mujeres), en la cual la organización defiende que "las transformaciones sociales que la revolución promovió habrían contribuido a la emancipación de la mujer al rechazar valores tradicionales y coloniales", pese a que 


\section{Mujeres angoleñas en la lucha anticolonial: historiografía, fuentes y memoria}

no haya considerado las relaciones desiguales entre hombres y mujeres como una contradicción principal dentro del propio MPLA (Paredes, 2015, 59).

Paredes hace también referencia al artículo titulado "Men in Our Country Behave Like Chiefs, Women and the Angola Revolution" (Los hombres de nuestro país se comportan como jefes, las mujeres y la revolución de Angola) de Catherine V. Scott, publicado en 1984, en el libro Women and Revolution in Africa, Asia and the New World (Mujeres y revolución en África, Asia y el Nuevo Mundo), en el que critica a la OMA por evitar el análisis de género dentro del MPLA, sin tomar en consideración la opresión masculina sobre las mujeres del partido (Paredes, 2015, 63).

El artículo de la investigadora holandesa Inge Brinkman (2003), "War, witches and traitors: cases from the MPLA's Eastern Front in Angola (1966-1975)" (Guerra, brujas y traidores: casos del Frente Oriental del MPLA en Angola 1966-1975), trata de las acusaciones, juicios y ejecuciones de brujas y traidores en el Frente Oriental del MPLA en Angola. Según la estudiosa, estos eventos no son parte del retrato general del MPLA como movimiento socialista y secular, apoyado por la población angoleña sin recurrir a la fuerza. El texto aborda cuestiones de género en la guerrilla, así como, de modo tangencial, la política del MPLA en el interior del país durante la guerra.

De los trabajos aquí analizados, se percibe, por tanto, un mayor número de publicaciones en los países de lengua inglesa, habiendo así la necesidad de mayor circulación del tema en los países de lengua portuguesa, yendo más allá de los artículos, tesis de maestría y doctorado, con investigaciones que densifiquen las múltiples perspectivas de la participación de las mujeres angoleñas.

\section{Consideraciones finales}

En Angola, los feminismos africanos se constituyen a partir de los años setenta del siglo XX, no precisamente como grupos sino más bien a partir de la elaboración de una serie de reflexiones. Anteriormente, hubo "movimientos" de mujeres angoleñas que en las luchas por la independencia combatieron al "lado de los hombres". No se dio, por tanto, un diálogo explícito entre el movimiento de esas mujeres de la lucha armada y la lucha feminista, pese a que sus ideas de resistencia y enfrentamiento estuvieran presentes en sus prácticas.

Las luchas de liberación sirvieron como base de formación para el surgimiento de la organización de mujeres dentro de los movimientos de lucha armada $y$, posteriormente, de los feminismos africanos.

Al mismo tiempo, las narrativas de combate a la colonización fueron construidas en masculino y las mujeres ocuparon un espacio periférico en tales discusiones, a pesar de que participaron activamente en todos los frentes de combate. Por este motivo, mi exposición enfatizó, en primer lugar, en algunos debates de los feminismos africanos para después abordar una reflexión sobre el campo historiográfico e interdisciplinar de los estudios sobre mujeres y género en Angola. Entiendo que ese diálogo está presente, aunque por momentos aparezca apenas implícito. 


\section{Dayane Augusta Santos da Silva}

En el transcurso de este artículo percibo la constitución de un campo de investigación temático e historiográfico de estudios de género y la participación de las mujeres en las guerras de liberación de Angola. Debido a las condiciones de guerra, la investigación se convirtió en una actividad compleja y la aproximación a la participación de las mujeres rurales anónimas fue infrecuente; los imperativos de la construcción nacional encapsularon los relatos históricos en la conformación de figuras míticas o "heroínas", representando a mujeres que habían participado en los combates. Con la excepción del trabajo de Kassembe y Chiziane, se percibe, sin embargo, un interés en las narrativas que abordan las experiencias de mujeres integrantes de la OMA/MPLA. Esto revela indicios de un mayor problema respecto a la producción de las fuentes escritas, que no se perdieron en el transcurrir de las guerras y que por tanto, son accesibles a los investigadorxs. Por dar un ejemplo, es posible acceder a registros documentales que no están en las instituciones públicas sino bajo la tutela de ciertas personas que han conservado documentos, material privado, etc. En ese contexto de guerras, cualquier persona puede adquirir un documento. Estas y otras prácticas de conservación de fuentes escritas no producen un archivo en el sentido oficial, pese a que reconstituyan la idea del documento como instrumento político e ideológico.

Este campo de estudios se ha ido expandiendo gracias a dinámicas epistemológicas propias y endógenas de investigadores e investigadoras angoleñas en el análisis de temas, tratamientos diferenciados, recolección de testimonios, fuentes escritas y producción bibliográfica. Tales estudios intentan responder a sus propias cuestiones y satisfacer las necesidades, tanto intelectuales como materiales, de producción científica sobre/de su sociedad, incluso frente a las tensiones entre memoria/recuerdo/evocación del pasado y de la producción de los discursos sobre este pasado-presente. La agenda de investigación desarrollada dentro del campo intelectual angoleño en el presente siglo se enriquece de los aportes relevantes realizados desde Brasil (Daiana Castilho Dias), Portugal (Margarida Paredes) y Estados Unidos (Marisa Mormanm y Selina Makana).

En este momento en que las conquistas de las mujeres ganan un mayor impulso, considero que el campo, como un área de conocimiento sistematizado, está adquiriendo formas más definidas con trabajos como el de Henda Ducados (2000), Emerlinda Liberato (2016) y Aurora Fonseca Ferreira (2018). Intelectuales angoleñas que cuestionan las estructuras y discuten las condiciones de vida de las angoleñas, y en particular sus posiciones en la sociedad, evidenciando la violencia y las negligencias frente a los constantes abusos contra las mujeres. Estas investigadoras valoran no sólo la historia de las mujeres sino también los estudios de género con interés en reforzar la agenda de emancipación y empoderamiento de las mujeres como parte del legado de la lucha anticolonial. A pesar de esto, todavía no existe en Angola un centro de estudios de género propiamente dicho, con vistas a fomentar más investigaciones en dicha área.

Pretendí, por tanto, realizar un análisis historiográfico panorámico sobre la escritura de la historia de las mujeres en Angola, pero también en el exterior. 


\section{Mujeres angoleñas en la lucha anticolonial: historiografía, fuentes y memoria}

Respecto a la participación de las mujeres en la guerra, sus debates y significados en la escritura de la Historia, puede afirmarse que las discusiones han oscilado en torno a las discusiones sobre representaciones de las grandes narrativas de carácter ejemplar, las actividades y discursos de organizaciones femeninas, más concretamente de la OMA/MPLA y la experiencia de mujeres anónimas. Avanzando dentro de lo que las condiciones que los testimonios orales y registros escritos permiten.

Después de años de guerra y la construcción de sus propios procesos democráticos en el largo período poscolonial, pensar en Angola requiere equilibrar y reformular ideas, narrativas y marcos teóricos. Las fuentes orales y escritas, que no son tan escasas como imaginamos, son herramientas importantes en este proceso de reflexión.

\section{Bibliografía}

Barnet, D. \& Harvey, R. (1972). The Revolution in Angola, MPLA, Life Histories and Documents. New York: Campus Verlag.

Batsîkama, P. (2016). A mulher na luta de libertação e na construção do EstadoNação em Angola: o caso de Luzia Inglês Van-Dúnem. Revista Cantareira, (25).

Batsîkama, P. (2020). Poder no Feminino. Caso da Deolinda Rodrigues "Langidila". Revista Áfricas. 7, (13).

Bittencourt, M. (2002). Estamos juntos! O MPLA e a luta anticolonial (1961-1974). (Tesis de Doctorado). Universidad Federal Fluminense, Brasil.

Brinkman, I. (2003). War, Witches and traitors: cases from the MPLA's Eastern Front in Angola (1966-1975). The Journal of African History, (44).

Castilho Dias, D. (2002). Um outro lado da Guerra colonial. História das Mulheres que participaram da luta pela libertação de Angola (1961-1975) (Tesis de Maestría) Brasilia, Brasil.

Cirne, M. (2017). A produção necessária das intelectuais feministas africanas no campo dos estudos de gênero e a agência do Codesria. Revista África(s), 4, (8).

Costa, R. (2014) Colonialismo e gênero entre os Ovimbundu: relações de poder no Bailundo (1880-1930) (Tesis Doctorado en Historia). Universidad de Brasilia, Brasil.

Curto, J. (2016). The Donas of Benguela,1797: A preliminary Analysis of a Colonial Female Elite. En Pantoja et al. (orgs.) Angola e as angolanas: memória, sociedade e cultura. São Paulo: Intermeios. 


\section{Dayane Augusta Santos da Silva}

Ducados, H. (2000). Angolan Women's Survival in Times of War in an All-Men's Show, London. Disponible en: http://www.angonet.org/docs/pmu/Angolan\%20Women's\%20Survival\%20\%20Henda\%20Ducados.pdf.

Ferreira, A. (2018). A contribuição da mulher na formação do saber e do conhecimento. En I. Mata, I \& L. Cavalcante Padilha, A mulher em África. Vozes de uma margem sempre presente. Lisboa: Edições Colibri.

Kasembe, D. \& Chiziane, P. (2008). O livro da paz da mulher angolana: as heroínas sem nome. Luanda, Angola: Nzila.

Kasembe, D. (2010). As mulheres honradas e insubmissas de Angola. Luanda Sul/Angola: Mayamba.

Liberato, E. (2016). 40 anos de Independência. Uma reflexão em torno da condição da mulher angolana. Estudos Feministas, Florianópolis, 24 (3). Disponible en: https://www.scielo.br/scielo.php?pid=S0104-

$\underline{026 X 2016000300997 \& \text { script }=\text { sci abstract\&tlng=pt. }}$

Makana, S. (2017). What the Body Remembers: Traumatic Narratives of War and the Wounded Female Body as Witness. En The War Needed Women: Gender and Militarization in Angola, 1961-2002 (Degree of Doctor of Philosophy). University of California: Berkeley.

Mbembe, A. (2001). As formas africanas de auto-inscrição. Estud. afroasiát. [online], 23, (1).

Meneses, M. P. (2017). Autodeterminação em Moçambique: Joana Semião, entre a história oficial e as memórias de luta. En I. Mata (Coord.) Discursos memorialistas africanos e a construção da História. Macau: Edições Colibri.

Moorman, M. J. (2004). Dueling bands and good girls: Gender, music, and nation in luanda's musseques, 1961-1974. International Journal of African Historical Studies, 37, (2).

Moorman, M. J. (2016). Intimating Nationalism: Gender in the MPLA's maquis. En S. Pantoja; E. Bergamo; A. C. da Silva (Org's) Angola e as angolanas: memória, sociedade e cultura. São Paulo: Intermeios.

Oliveira, V. (2018), Donas pretas livres e escravas em Luanda (séc. XIX). Estudos Ibero-Americanas, 44 (3).

OMA - Organización de la Mujer Angoleña (1984). Angolan Women Building the Future, from National Liberation to Women's Emancipation. London: Zed Books.

Pantoja, Selma (2004). Conexões e identidades de gênero no caso Brasil e Angola, Sécs. XVIII $\mathrm{e}$ XIX. Disponible en http://bibliotecavirtual.clacso.org.ar/ar/libros/aladaa/pantoja.rtf. 


\section{Mujeres angoleñas en la lucha anticolonial: historiografía, fuentes y memoria}

Pantoja, Selma (2016). Historiografia africana e os ventos sul: desenvolvimento e história. Transversos: Revista de História, (8).

Paredes, M. (2010). Deolinda Rodrigues, da família metodista à família MPLA, o papel da cultura na política. Cadernos de estudos africanos, (20). Disponible en https://revistas.rcaap.pt/cea/article/view/8306

Paredes, M. (2015). Combater duas vezes - Mulheres na Luta Armada em Angola. Lisboa: Editora Verso da História.

Paredes, M. (2017). Biografias, memórias coloniais e legados pós-coloniais. Revista Ideação, 1 (35).

Rabello, R. (2017). Dya Kassembe e a representação das vozes de mulheres angolanas. Caderno Seminal Digital, 27, (27).

Reis, M. (1987). Représentation sociale de la Femme dans le Discours Nationaliste: Le cas de la Génération des années 50 em Angola. África, Revista do Centro de Estudos Africanos da USP, (10).

Scott, C. (1994). Men in Our Country Behave Like Chiefs, Women and the Angola Revolution. En M. A. Tétrault (Org) Women and Revolution in Africa, Asia and the New World. South Carolina: University of South Caroline Press.

Sow, F. (1997). The social sciences in Africa and gender analysis". En A. Iman; A. Mama; F. Sow, (eds.) Engendering African Social Sciences. Dakar: CODESRIA Book Series apud.

Spivak, G. (2010). Pode o subalterno falar?, 1. ed. Trad. Sandra Regina Goulart Almeida; Marcos Pereira Feitosa; André Pereira. Belo Horizonte: Editora da UFMG.

Zeleza, P. (1997). Gender biases in African historiography. En A. Imam; A. Mama; F. Sow (eds). Engendering African Social Sciences. Dakar: Codersia. Disponible en: https://www.cognella.com/pdf/korieh sneak preview.pdf

\section{Fuentes}

Provincia de Angola

Diário de Luanda

Semanário de Opinião e Informação

\section{Archivos}

Archivo de la Biblioteca Nacional de Angola

Recibido: 30/11/2020

Evaluado: 20/01/2021

Versión Final: 24/02/2021 